\title{
A New Integrated Teaching Mode for Labor Education Course Based on STEAM Education
}

\author{
https://doi.org/10.3991/ijet.v17i02.28461 \\ Hongbo Xue \\ College of Mechanical Technology, Wuxi Institute of Technology, Wuxi, China \\ xuehb@wxit.edu.cn
}

\begin{abstract}
In the current market full of the competition of talents, the current education has focused on how to cultivate the talents needed by the market, and STEAM education concept has also attracted widespread attention. STEAM education is a problem-oriented approach that can effectively improves students' independent thinking and problem-solving ability through multidisciplinary education. Since its proposal, it has been applied to many disciplines, including the labor education course. As a typical interdisciplinary course integration approach based on real scenario theme has provided new ideas for transboundary integration of labor education course. On this basis, the application of STEAM education concept in labor education curriculum was analyzed in detail in this paper to establish a new-type teaching method integrating science, technology, engineering, art, and mathematics while combining the problem-oriented thinking process. Correspondingly, according to the characteristics of the Bayesian network, a college student labor education course online self-study model was established. The Bayesian network mode and nondirective teaching mode were introduced to effectively improve the teaching effect of labor education courses. The study has found that after applying STEAM-based integrated teaching mode in labor education course, students' labor education course grade, labor skills, self-learning capacity, excitation exploration ability, analytical competence, team spirit, and sense of participation have significantly enhanced, indicating that this teaching mode is significantly superior to traditional teaching methods.
\end{abstract}

Keywords-STEAM education, non-directive teaching, labor education,

Bayesian network

\section{Introduction}

Labor technology education is the primary method for schools to combine education with production labor, and as well as the foundation to implement education guidelines integrating education with production labor, cultivate students' all-round ability in areas such as morals, intelligence, physical fitness, work and aesthetics [1]. In fact, the education circles have highly valued the reform of the labor education, and labor education course has also evolved throughout five stages of exploration, special 
development, innovation, deepening, and construction in the new era. Great changes have happened in textbooks and curriculum settings. However, influenced by examoriented education, schools at all levels have not paid enough attention to labor education course or the effect is poor, which is not conducive to the reform of the labor education course [2]. In view of this, in order to promote labor education curriculum reform and strengthen the effectiveness of labor education course, and promote students' all-round ability in areas such as morals, intelligence, physical fitness, work and aesthetics, paper is, a labor education teaching mode based on STEAM education concept was proposed in this paper, aiming to cultivate comprehensive all-around talent.

Despite the research on the labor education course by a lot of scholars, many have elaborated issues in the labor education course, and some research papers on the teaching strategies are abstract with less practical value. Therefore, in this paper, STEAM education concept was introduced in this paper, aiming to implement interdisciplinary teaching of labor education course with problem oriented and cultivate all-round talents for the society, which is the mainly advocated in current education reform. At the same time, non-directive teaching mode was applied based on STEAM education concept, which can facilitate the implementation of STEAM in the practice of labor education course. In addition, considering the high-speed development of information technology and the adoption of online and offline teaching of labor education course, Bayesian network model was also introduced, and student labor education course online self-study model was established, so as to improve the teaching effect of labor education course, strengthen students' class participation and initiative, and improve their independent thinking and problem-solving ability.

\section{State of the art}

A lot of scholars have been studied the educational teaching mode and involved many teaching methods, such as STEAM education concept, non-directive teaching, and Bayesian teaching model, which have also established mature theory. Regarding the research on the application of STEAM education concept in education teaching model, the "Undergraduate Science, Mathematics and Engineering Education" issued in the United States has emphasized that science disciplines and mathematics are of great significance to education [3]. With the high-speed development of society, American educators have proposed STEAM education concepts in "Shaping the future: Perspectives on Undergraduate Education in Science, Mathematics, Engineering, and Technology", which has also become an important part of American education. Subsequently, officially integrated into STEM concept, art has become today's STEAM education concept. Blinkov et al. [4] believed that STEAM education concept as a method of educating innovative talents can guide students to break conventional thinking in solving relevant problems, and adopt various advanced technologies. Because of this characteristic, STEM education concept was also included into education reform strategy at the K-12 stage. Chinese scholars have also conducted a great number of studies. For example, in order to improve the quality of kindergarten 
labor education course, $\mathrm{Li} \& \mathrm{Wu}$ [5] adopted STEAM education concept to design course. It was believed that STEAM teaching content in accordance with children's cognitive rules and children's interest should be formulated, labor education content should be designed reasonably, so as to improve the comprehensive STEAM literacy of children through interdisciplinary labor education activities to promote children's comprehensive quality. After studying the application of STEAM education concept in primary school labor and technology design special activity, Li \& Wu [6] believed that STEAM education concept significantly primary school labor and technical course after being applied to each link of primary school labor classroom teaching due to its strong comprehensiveness and practicability. Therefore, the author believes that STEAM education concept should be fully utilized in primary education.

The application of non-directive teaching and Bayesian teaching model in education has been studied by many scholars. For example, Di Pietro et al. [7] studied the application of Bayesian network model in higher education and believed that it has yielded satisfactory effect in higher education and also enhanced students' satisfaction and loyalty to the course due to its full consideration of students' various needs, expectations, etc. Eliasquevici et al. [8] studied the application of Bayesian network teaching model in distance education, and believed that Bayesian network teaching model helped effectively evaluate the effect of distance education, and then benefited distance education. It was found by Kim et al. [9] through problem-oriented study of the application of Bayes network in computer education based on STEAM that the entire computer education process with target enhanced students' independent problem-solving ability, and the application of the Bayesian network model also enhanced the effect of computer online education. Peng et al [10] diagnosed and certified the online course learning results based on the Bayesian network, and believed that the learning output-oriented Bayesian network model played an important role for the diagnosis of learners' professional ability and knowledge structure. The author has also added data XML binding, embedded evaluation results and learning results in online education to better measures online education effect. Xing [11] studied the application of non-directive teaching mode in language preview teaching, and found that "non-directive preview" model can facilitate students' autonomous learning, mobilize students to actively study the logic of text in Chinese preview process, strengthen students' critical and independent thinking, thereby obtaining the efficiency of Chinese teaching.

It can be seen from aforementioned research that despite many scholars' study on the application of STEAM education concept, non-directive teaching, and Bayesian teaching mode in education, few scholars have integrated these teaching modes. In fact, teaching modes can be fused to give full play to their respective advantages, thus enhancing the teaching effect. In view of this, taking the labor education course as an example, this paper is focused on studying the application of STEAM-based integrated teaching mode, which also integrates non-directive teaching and Bayesian teaching mode. 


\section{Integrated teaching mode based on STEAM education concept in labor education course}

\subsection{STEAM education concept}

The so-called STEAM concept refers to multi-subject education including Science, Technology, Technology, Technology, Engineering, ARTS (Art), Mathematics (Mathematics), etc. [12]. Unlike traditionally specific subject education, and textbook-based education method, STEAM advocates that teaching requires to be implemented by a variety of scientific joint implementation rather than merely a science. Initially proposed by the US government to improve children's comprehensive litera$\mathrm{cy}$, and then enhance their market competitiveness, so that they truly become talents needed in practice. The STEAM concept was firstly proposed by the Ministry of Education proposed in "Guiding Opinions on Comprehensively and Deeply Promoting Education Informatization during the" Thirteenth Five-Year Plan "(Draft for Comment)". STEAM concept is shown in Figure 1:

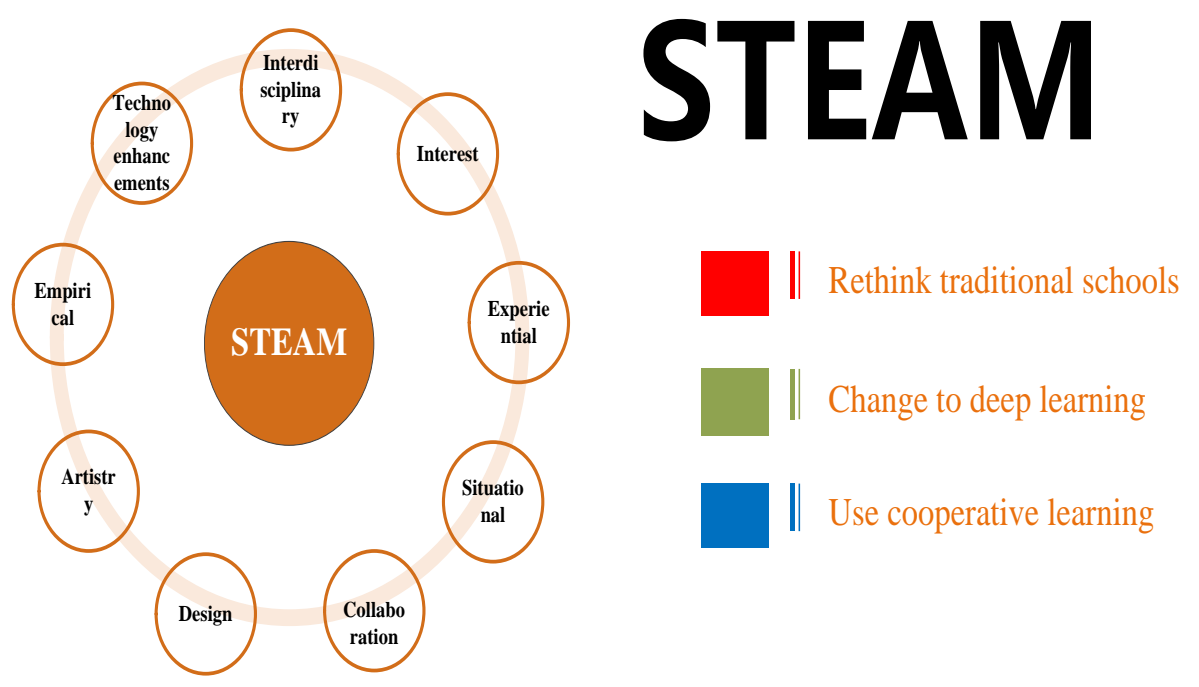

Fig. 1. STEAM education concept

Aiming to ad ultimately develop children's independent thinking and problemsolving ability through interdisciplinary education, STEAM concept focuses on solving the problem. In order to achieve this goal, it is necessary to pay attention to the integration between disciplines when applying the concept. In addition, STEAM concept also emphasizes the process exploration. The former integrates with knowledge points in five disciplines of science, technology, engineering, art, mathematics, and the latter emphasizes problem-oriented thinking process cultivation, specifically shown in Figure 2: 

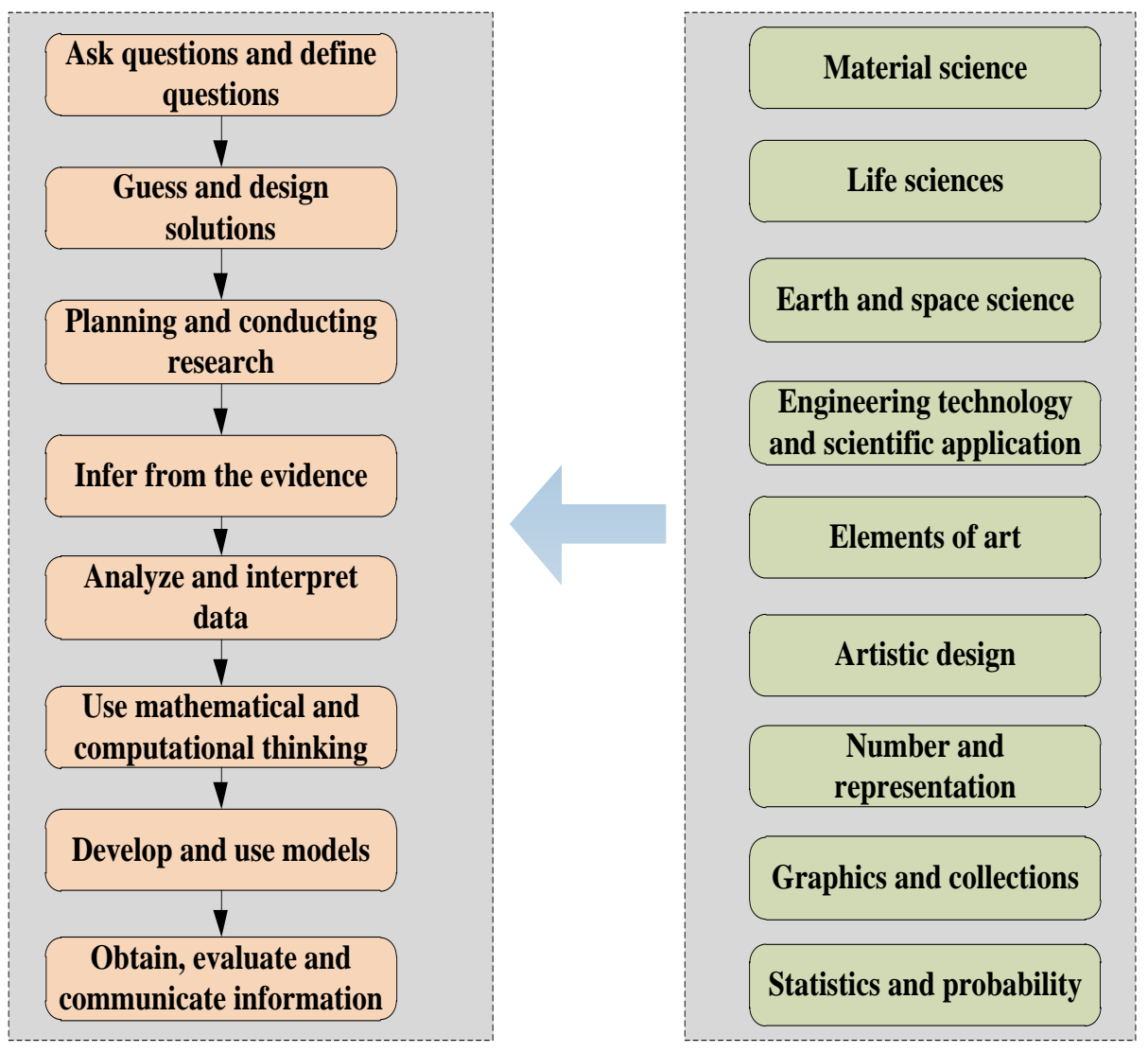

Fig. 2. The application of STEAM concept in education

Figure 2 shows that the application of STEAM concept in education involves nine fields, including material science, life science, earth and space science, engineering technology and scientific applications, artistic elements, art design, number and representatives, graphics and set, statistical and probability. STEAM concept is applied throughout the whole thinking process from raising problems, defining problems, guessing and designing solutions, planning and conducting research, deduction according to the evidence, analyzing and explaining data, using mathematics and calculation thinking, developing and using model, eventually acquiring, evaluating and conveying information.

\subsection{College student labor education course online self-study model based on Bayesian model}

In addition to STEAM education concept, a student online course self-study model based on Bayesian model was applied in this study when designing college labor education course. Bayesian model is a graphical model including not only priori 
knowledge but also posterior knowledge. Through the integration of these two types of knowledge, the probability relationship between variables and the related causal mechanisms in the environment can be finally obtained. According to this feature of Bayesian network, college student labor education course online self-study model is established in this study.

\section{Overview of Bayesian model}

Bayesian theory was proposed by the famous Mathematician Bayes, specifically as follows:

$$
P(H \mid E, c)=\frac{P(H \mid c)^{*} P(E \mid H, c)}{P(E \mid c)}
$$

Among them, $P(H \mid c)$ is prior probability, $P(H \mid E, c)$ is posterior probability. The formula indicates that given the priori knowledge $\mathrm{c}$ and additional evidence $\mathrm{E}$, the credibility $\mathrm{H}$ for hypothesis $\mathrm{H}$ can be obtained.

\section{Bayesian network}

Based on the aforementioned Bayesian theory, Bayesian network $B N\left(B_{S}, B_{P}\right)$ was constructed, where $B_{S}$ is a directed acyclic graph defined on the node set $\mathrm{V}$, and $B_{P}$ is a probability distribution function, namely:

$$
B_{P}=\left\{P\left(X_{i} \mid p a_{i}\right)[0,1] \mid X_{i} \in V\right\}
$$

That is, given a discrete variable combination $\mathrm{X}$ and a directed acyclic graph, there exists a one-to-one correspondence between the variables in $\mathrm{X}$ and the nodes on the directed acyclic graph. Thus, recursive product decomposition of the joint probability distribution function $\mathrm{P}$ can be performed, as shown in the following formula (3).

$$
P\left(X_{i}\right) \prod_{i} P\left(X_{i} \mid p a_{i}\right)
$$

In the recursive decomposition formula, each variable $\mathrm{X}_{\mathrm{i}}$ also satisfies with Markov independence, namely:

$$
X_{i} \perp\left\{X_{1}, X_{2}, \cdots, X_{i-1}\right\} / p a_{i} \mid p a_{i}
$$

In Bayesian network, a minimum subset $\pi_{i}$ not independent with the variable condition can be found, which satisfies the following:

$$
\pi_{i} \subseteq\left\{X_{1}, X_{2}, \cdots, X_{i-1}\right\}
$$

It also satisfies: 


$$
P\left(X_{i} \mid X_{1}, X_{2}, \cdots X_{i-1}, \varphi\right)=P\left(X_{i} \mid \pi_{i}, \varphi\right)
$$

In addition, the minimum subset $\pi_{i}$ is also the parent node of $\mathrm{X}$ in Bayesian network, satisfies the following:

$$
P(X \mid \varphi)=\prod_{i=1}^{n} P\left(X_{i} \mid P_{a_{i}}, \varphi\right)
$$

Therefore, $B N\left(B_{S}, B_{P}\right)$ constitutes a Bayesian network structure.

\section{D-separation}

Markov independence indicates that each variable $\mathrm{X}$ is conditionally independent of other ancestors $\left\{X_{1}, X_{2}, \cdots, X_{i-1}\right\} / p a_{i}$. This characteristic can also be expressed by "D separation" in the directed acyclic graph. Suppose X, Y, Z are three separate nodes belonging to a node set in the directed acyclic graph, if and only if there is no path from one of the nodes in $\mathrm{X}$ to a node in $\mathrm{Y}$ that makes the aggregation node in $\mathrm{Z}$, then $\mathrm{Z}$ is $\mathrm{D}$ separated from $\mathrm{X}$ in $\mathrm{Y}$, specifically satisfies the following:

$$
P(X, Y, Z)=P(X) * P(Z \mid X) * P(Y \mid Z)
$$

\section{Process of Bayesian network establishment}

Assuming that $\mathrm{n}$ random variables in the model, i.e., $\left\{X_{1}, X_{2}, \cdots, X_{n}\right\}$, and assuming that $X_{i}$ can only be 1 or 0 , under the circumstance the total probability formula will have $2^{\mathrm{n}}$ probability. The total probability formula is:

$$
P(X)=P\left(X_{1}, X_{2}, \cdots, X_{n}\right)
$$

Bayesian network can make the whole calculation simple. To establish Bayesian network, it firstly requires to determine the variable related to the model. Second, it is necessary to build an independent directed acyclic graph, thus the probability distribution formula is obtained:

$$
P(X)=\prod_{i=1}^{n} P\left(X_{i} \mid X_{1}, X_{2}, \cdots, X_{i-1}\right)=\prod_{i=1}^{n} P\left(X_{i} \mid P_{a_{i}}\right)
$$

5. Design of student self-study model based on Bayesian network

The construction of college student labor education course online self-study model based on Bayesian model from the perspective of information flow essentially aims to obtain relevant model by processing information related to students. The specific design process is shown in Figure 3: 


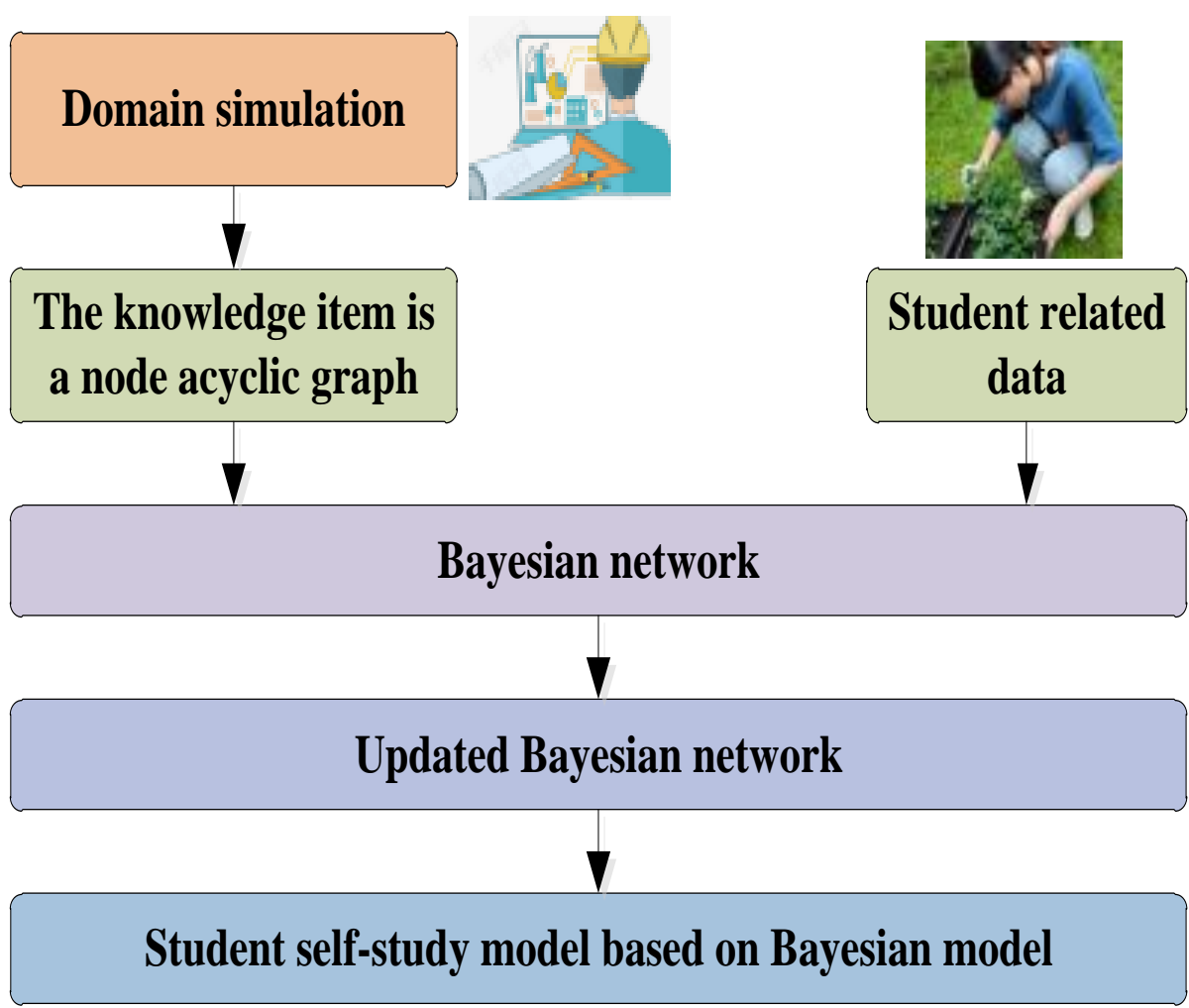

Fig. 3. Design of student self-study model based on Bayesian network

The college student labor education course online self-study model based on Bayesian model is mainly established according to students' self-study characteristics according to Bayesian network theory, where relevant information will be divided into domain-independent information and domain-dependent information. Among them, domain-dependent information has direct or indirect impact on students' learning, such as gender, age, learning interest, learning attitude, etc. Starting from the information, based on the directed acyclic graph with knowledge item as node, the Bayesian model that satisfies college student labor education course online self-study demand can be established. Through model improvement and updating based on the data, college student labor education course online self-study model based on Bayesian model is finally constructed.

\subsection{Integration of non-directive teaching mode in the teaching of labor education course}

College labor education course should also be integrated into the non-directive teaching mode, that is, during the problem-oriented teaching process, students are encouraged to learn various knowledge points, to think about various problems, make 
independent judgment, independent reflection and autonomous error correction, and independent growth. Therefore, the application of non-directive teaching mode in labor education course will eventually help students enhance themselves by means of courseware. The mode is shown in Figure 4:

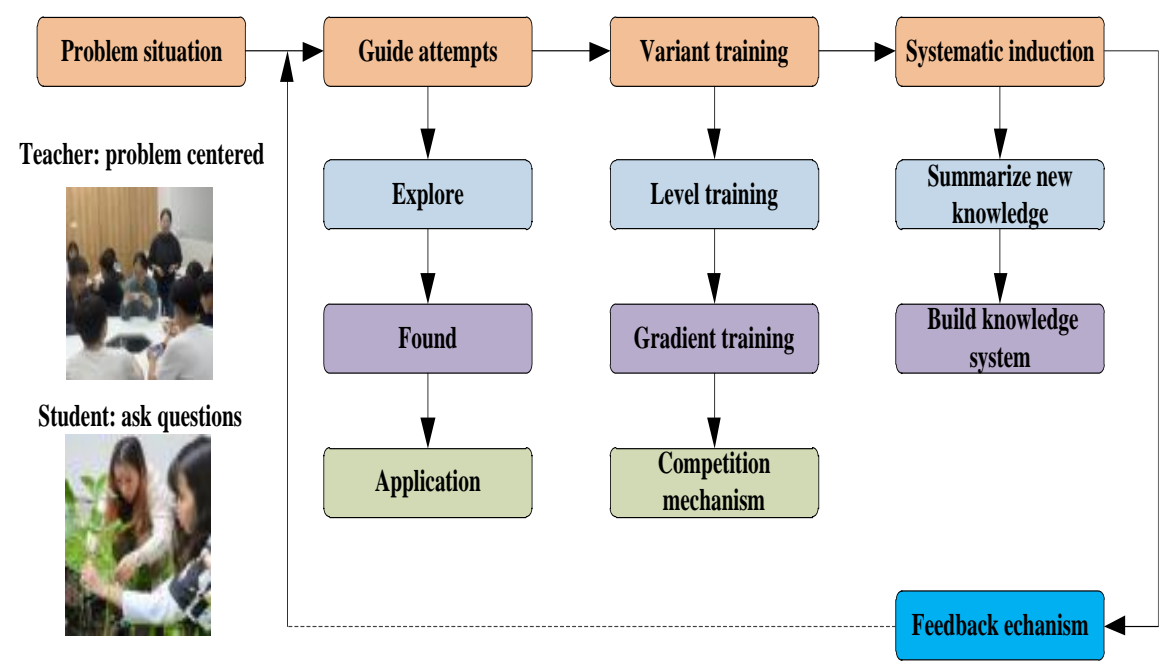

Fig. 4. Application of non-directive teaching mode in the teaching of labor education course

As shown in Figure 4, non-directive teaching mode is focused on cultivating students' self-study ability. "Non-directive" teaching mode mainly requires students to actively participate in actual teaching activities and give full play to students' ability to use brain and hands. To achieve the goal, after completing online self-study based on Bayesian network, teachers, with these problems, guide students to try, explore, and find causes for these problems, and try to solve these problems. In order to improve students' problem-solving ability, teachers can also arrange the training by different levels and gradients. In the training process, teachers can find students' deficiencies in independent learning, and finally systematically summarize new knowledge points, and construct a complete knowledge system. At the same time, they can also provide feedback in the process to guide the subsequent teaching. It can be seen that in the labor education course, the non-directive teaching mode helps create problem scenario for teachers after instructing the knowledge point in each link, and guide students to solve various problems, and finally establish systematic knowledge system. Therefore, applying non-instructive teaching mode in labor education course is conductive to enhancing the teaching effect of the labor education course. 


\section{$4 \quad$ Teaching example and effect}

\subsection{Teaching example}

Based on the aforementioned STEAM education concept, Bayesian network model, and labor education course created by non-directive teaching mode, in this study, taking "flower arrangement" of labor education course as an example, the application of STEAM-based integrated teaching mode labor education course can be better understood. According to above description, the teaching mode is shown in Figure 5.

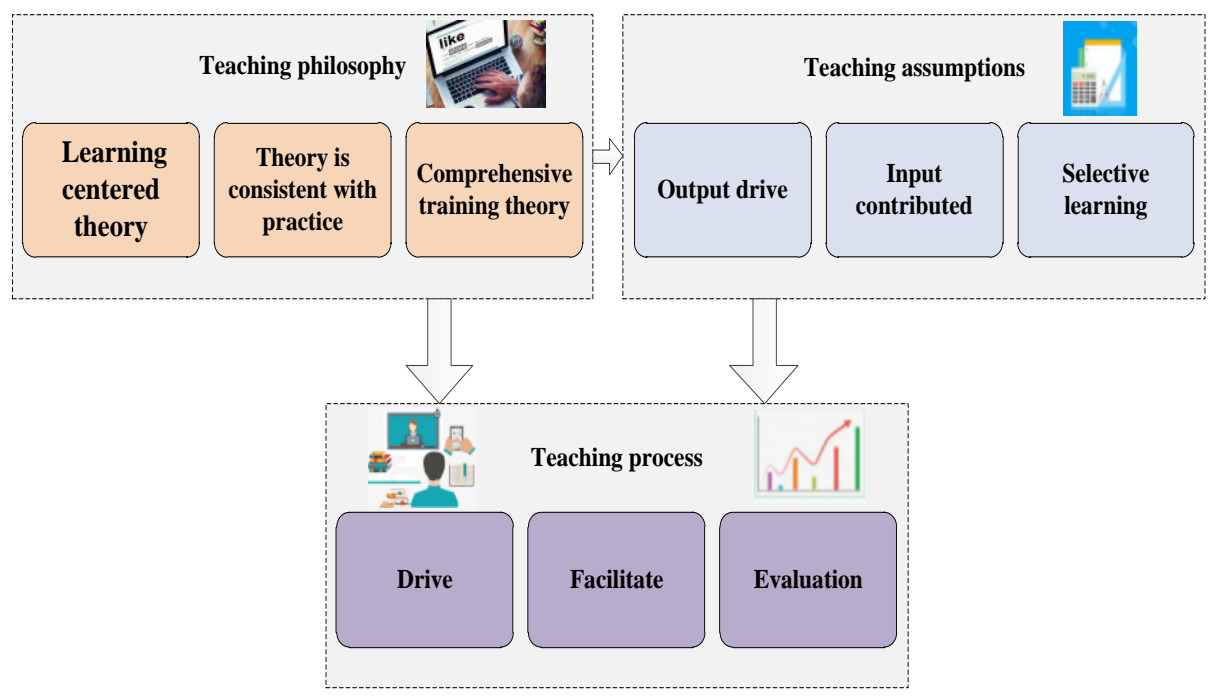

Fig. 5. Application of STEAM-based integrated teaching mode in flower arrangement course

Under the teaching mode, before class, teachers make full use of the Bayesian network-based online self-study course model to guide students to carry out "flower arrangement" course. On this basis, with problem oriented, teachers guide students in the class by following STEAM education concept, and the non-directive teaching mode, so as to strengthen students' mastery of flower arrangement theoretical knowledge. After class, teachers should sort out teaching knowledge to establish new knowledge system. Figure 6 displays the teacher-student interaction based on STEAM education concept. 

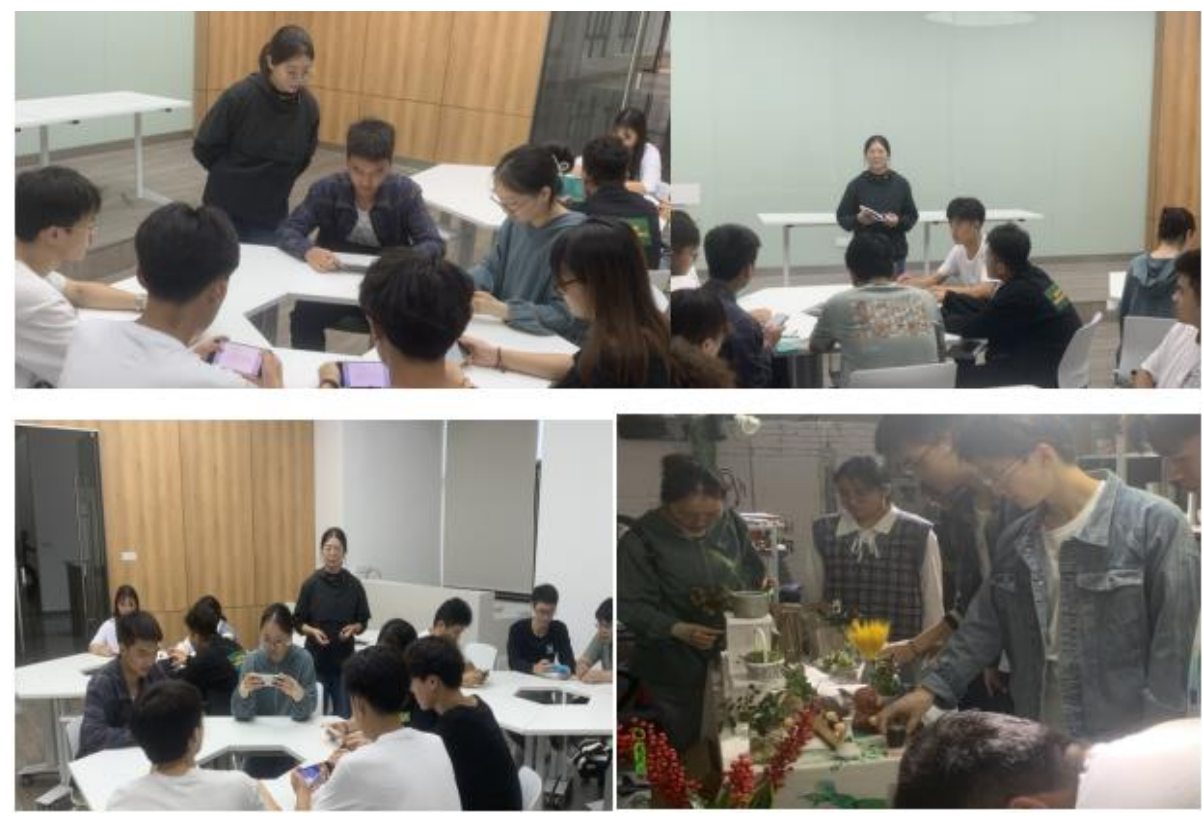

Fig. 6. Display of classroom teacher-student interaction based on STEAM education concept

In accordance with Figure 5, application of STEAM-based integrated teaching mode in flower arrangement course can be divided into three stages: pre-class stage, in-class stage and after-class stage.

Among them, at pre-class stage, teachers upload teaching course for students to conduct online self-study. The entire self-study process will be integrated in online self-study course mode based on the Bayesian network, by which students can acquire a basic understanding of flower arrangement in spring, summer, autumn, winter and floral bottles, dishes, bowls, cartridges, baskets, and pot, obtain a preliminary mastery of the creation skills of the flower arrangement.

At in-class stage, teachers first set up questions, such as key points of the oriental traditional flower arrangement art creation. Teachers guide students to explore the design points of oriental flower arrangement based on non-directive teaching mode and STEAM concept. For example, teachers can guide students to use different flower materials to display setting-out, up-right, hang-down and inclination with different themes, so that students can experience the feelings of different displays. Teachers can also encourage students to discuss the art of inserting flowers with different flowers, different utensils, and different operating skills, to create their own works. In the end, they can improve the works through students' mutual evaluation and teachers' comments.

After class, students summarize the characteristics of each work, comment the advantages and disadvantages of each work, and discuss deepen the understanding of the theoretical knowledge of oriental traditional flower arrangement. With a mastery 
of relevant technical points, they can finally summarize new flower arrangement technology system.

\subsection{Teaching effect}

In this study, 153 college students of grade 2020 majoring in flower arrangement were randomly selected as research objects, including 76 in the control group and 77 in the experimental group. The teaching objectives, online education course, and teachers for two groups were the same. Two groups had no statistical significance in terms of the age and gender of students, and two groups had comparability.

At the preparation stage: Teachers learn multimedia technology, grasp the specific application of multimedia teaching methods, look up relevant literature and data based on the teaching goal of "flower arrangement" course, and get prepared for "flower arrangement" related online course.

At the implementation stage: students in the control group were given interference. Students were provided with labor education course online and offline teaching similar to the previous semester, the relevant teaching schedule followed the teaching plan; STEAM-based integrated teaching mode was introduced to experimental group. Teachers carried out specific teaching by following STEAM education concept, Bayesian network and the non-directive teaching mode concept, improved the teaching mode according to process assessment results, teaching effects.

There are two main evaluation criteria: The first is the labor education course results of students in two groups at the end of the semester; The second is the students' learning effects, including labor skills, self-learning capacity, excitation exploration ability, analytical competence, team spirit, and sense of participation, etc.

The academic results of labor education course of students in observation group and the control group are shown in Table 1:

Table 1. Academic performance

\begin{tabular}{|l|c|c|}
\hline & Number of students & Average score \\
\hline Control group & 76 & $76.25 \pm 1.97$ \\
\hline Observation group & 77 & $82.33 \pm 2.03$ \\
\hline $\mathrm{t}$ & \multicolumn{2}{|c|}{8.009} \\
\hline $\mathrm{P}$ & \multicolumn{2}{|c|}{0.000} \\
\hline
\end{tabular}

As can be seen from Table 1, the "labor education" course scores of students in the observation groups are significantly higher than students in the control group, indicating that introducing STEAM-based integrated teaching mode to labor education course is conductive to increasing students' academic scores.

The learning effect of students in two groups was evaluated using return visit form and the results are shown in Table 2: 
Table 2. Learning effect

\begin{tabular}{|l|c|c|c|c|c|}
\hline & Labor skills & $\begin{array}{c}\text { Self-learning } \\
\text { capacity }\end{array}$ & $\begin{array}{c}\text { Excitation exploration } \\
\text { ability }\end{array}$ & $\begin{array}{c}\text { Analytical } \\
\text { competence }\end{array}$ & Team spirit \\
\hline $\begin{array}{l}\text { Control group } \\
(\mathrm{n}==76)\end{array}$ & $7.17 \pm 2.01$ & $7.09 \pm 1.91$ & $7.87 \pm 1.63$ & $7.32 \pm 1.77$ & $7.16 \pm 1.01$ \\
\hline $\begin{array}{l}\text { Observation group } \\
(\mathrm{n}==77)\end{array}$ & $7.89 \pm 2.18$ & $8.17 \pm 1.27$ & $8.42 \pm 1.09$ & $8.90 \pm 1.80$ & $8.73 \pm 1.42$ \\
\hline $\mathrm{t}$ & 7.189 & 8.107 & 8.817 & 8.421 & 7.982 \\
\hline $\mathrm{P}$ & 0.000 & 0.000 & 0.000 & 0.000 & 0.000 \\
\hline
\end{tabular}

As seen from the learning effect in Table 2, labor skills, self-learning capacity, excitation exploration ability, analytical competence, team spirit of students in the observation are significantly higher than students in the control group, further indicating that introducing STEAM-based integrated teaching mode to labor education course plays a significant role in improving learning effects. It has also proved the effectiveness of STEAM-based integrated teaching mode.

\section{Conclusions}

Based on STEAM education concept, integrating non-directive teaching and Bayesian teaching model, a teaching mode suitable for college students' characteristics has been established in this study. Through study, the teaching mode is proved to be effective when applied to labor education course. Specifically, the STEAM education concept was firstly introduced to determine the problem-oriented multidisciplinary comprehensive teaching mode. Then, by integrating Bayesian model into college labor education online self-study course, together with non-directive teaching mode, the STEAM-based labor education course online and offline teaching mode integrating Bayesian network and non-directive teaching mode was established. The study has shown:

1. STEAM is a problem-oriented interdisciplinary teaching concept, aiming to improve students' independent thinking and problem-solving ability. Students cultivated under STEAM concept are more comprehensive and practical, and they can better meet the needs of social development.

2. Applying STEAM-based integrated teaching mode in labor education course is conductive to enhancing students' labor education course scores, and also significantly improve the labor skills, self-learning capacity, excitation exploration ability, analytical competence, team spirit, and sense of participation of students.

3. Although a teaching model conductive to improving the teaching of labor education has been established thoroughly, limited by research experience and energy, the interaction between the three has not been analyzed in detail. Further research in this regard is required in the future. 


\section{Acknowledgement}

This research is supported by 2020 ideological and political special project of philosophy and social sciences research in Colleges and universities of Jiangsu Province (2020SJB0397).

\section{$7 \quad$ References}

[1] Shomirzayev, M.K. Developing educational technologiesin school technology education. Asian Journal of Multidimensional Research, 2021, vol. 10(5), pp. 73-79. http://dx.doi.org/ $10.5958 / 2278-4853.2021 .00377 .3$

[2] Qiang, B. Innovative Exploration of the Path of Labor Education in Colleges and Universities: Taking the Practice of Labor Education Informatization in Nanjing Audit University as an Example. The Education of Innovative Talents, 2019, vol. 7(3), pp. 76-80.

[3] Kricsfalusy, V., George, C., \& Reed, M. G. Integrating problem-and project-based learning opportunities: Assessing outcomes of a field course in environment and sustainability. Environmental education research, 2018, vol. 24(4), pp. 593-610. https://doi.org/10.1080/ $\underline{13504622.2016 .1269874}$

[4] Blinkov, V.N., Elkin, I.V., Emelianov, D.A., et al. Influence of nonuniformity of the submerged perforated sheet on steam demand leveling on the evaporation surface of a VVER steam generator. Thermal Engineering, 2016, vol. 63(1), pp. 51-55. https://doi.org/10.1134 /s0040601515120034

[5] $\mathrm{Li}, \mathrm{X} ., \mathrm{Wu}, \mathrm{H}$. Implementation strategy of kindergarten construction game under steam education concept. Early childhood education: Educational Science, 2018, vol. 15(11), pp. 3-4.

[6] Xu, J.P. Special activities of primary school labor and technology design under the concept of steam Education. New curriculum research, 2021, vol. 6(1), pp. 46-48.

[7] Di Pietro, L., Mugion, R. G., Musella, F., Renzi, M. F., \& Vicard, P. Reconciling internal and external performance in a holistic approach: A Bayesian network model in higher education. Expert Systems with Applications, 2015, vol. 42(5), pp. 2691-2702. https://doi.org/ 10.1016/j.eswa.2014.11.019

[8] Eliasquevici, M.K., da Rocha Seruffo, M.C., \& Resque, S.N.F. Persistence in distance education: A study case using Bayesian network to understand retention. International Journal of Distance Education Technologies (IJDET), 2017, vol. 15(4), pp. 61-78. https://doi. org/10.4018/ijdet.2017100104

[9] Kim, N.J., Belland, B.R., \& Walker, A.E. Effectiveness of computer-based scaffolding in the context of problem-based learning for STEM education: Bayesian meta-analysis. Educational Psychology Review, 2018, vol. 30(2), pp. 397-429. https://doi.org/10.1007/s10648 -017-9419-1

[10] Peng, X., Tan, M., Duan, B. Diagnosis and certification of online course learning results based on Bayesian network. Journal of Xiangtan University (Natural Science Edition), 2018, vol. 40(6), pp. 1-10.

[11] Xing, X.F. Efficient Chinese teaching should be based on non indicative preview. Education Research Monthly, 2019, vol. 25(6), pp. 94-102.

[12] Kricsfalusy, V., George, C., \& Reed, M. G. Integrating problem-and project-based learning opportunities: Assessing outcomes of a field course in environment and sustainability. 
Paper-A New Integrated Teaching Mode for Labor Education Course Based on STEAM Education

Environmental education research, 2018, vol. 24(4), pp. 593-610. https://doi.org/10.1080/ $\underline{13504622.2016 .1269874}$

\section{Author}

Hongbo Xue is a Lecturer in College of Mechanical Technology, Wuxi Institute of Technology, Wuxi, China.

Article submitted 2021-11-23. Resubmitted 2021-12-21. Final acceptance 2021-12-22. Final version published as submitted by the author. 